\title{
Comparison between anterior cervical discectomy with fusion and anterior cervical corpectomy with fusion for the treatment of cervical spondylotic myelopathy: a meta-analysis
}

\author{
This article was published in the following Dove Press journal: \\ Therapeutics and Clinical Risk Management \\ 17 November 2015 \\ Number of times this article has been viewed
}

\author{
Qi Fei* \\ Jinjun Li* \\ $\mathrm{Nan} \mathrm{Su}$ \\ Bingqiang Wang \\ Dong Li \\ Hai Meng \\ Qi Wang \\ jisheng Lin \\ Zhao Ma \\ Yong Yang
}

Department of Orthopaedics, Beijing Friendship Hospital, Capital Medical University, Beijing, People's Republic of China

*These authors contributed equally to this work
Correspondence: Yong Yang Department of Orthopaedics, Beijing Friendship Hospital, Capital Medical University, No 95, Yong'an Road, Xicheng District, Beijing 100050, People's Republic of China Tel +861063138353

Fax +861063138755

Email spineyang@।26.com
Background: Whether anterior cervical discectomy with fusion (ACDF) or anterior cervical corpectomy with fusion (ACCF) is superior in the treatment of cervical spondylotic myelopathy remains controversial. Therefore, we conducted a meta-analysis to quantitatively compare the efficacy and safety of ACDF and ACCF in the treatment of cervical spondylotic myelopathy. Methods: PubMed, Embase, Web of Science, SinoMed (Chinese BioMedical Literature Service System, People's Republic of China), and CNKI (China National Knowledge Infrastructure, People's Republic of China) were systematically searched to identify all available studies comparing efficacy and safety between patients receiving ACDF and ACCF. The weighted mean difference (WMD) was pooled to compare the Japanese Orthopaedic Association scores, visual analog scale scores, hospital stay, operation time, and blood loss. The risk ratio was pooled to compare the incidence of complications and fusion rate. Pooled estimates were calculated by using a fixed-effects model or a random-effects model according to the heterogeneity among studies.

Results: Eighteen studies (17 observational studies and one randomized controlled trial) were included in this meta-analysis. Our results suggest that hospital stay (WMD $=-1.33$, 95\% confidence interval $[\mathrm{CI}]:-2.29,-0.27 ; P=0.014)$, operation time (WMD $=-26.9,95 \%$ CI: $-46.13,-7.67 ; P=0.006$ ), blood loss (WMD $=-119.36,95 \% \mathrm{CI}:-166.94,-71.77 ; P=0.000$ ), and incidence of complications (risk ratio $=0.51,95 \% \mathrm{CI}: 0.33,0.80 ; P=0.003$ ) in the ACDF group were significantly less than that in the ACCF group. However, other clinical outcomes, including post-Japanese Orthopaedic Association score (WMD $=-0.27,95 \% \mathrm{CI}$ : $-0.57,0.03$; $P=0.075$ ), visual analog scale score (WMD $=0.03,95 \% \mathrm{CI}:-1.44,1.50 ; P=0.970$ ), and fusion rate (risk ratio $=1.04,95 \% \mathrm{CI}$ : $0.99,1.09 ; P=0.158$ ), between the two groups were not significantly different.

Conclusion: Evidence from the meta-analysis of 18 studies demonstrated that surgical options of cervical spondylotic myelopathy using ACDF or ACCF seemed to have similar clinical outcomes. However, ACDF was found to be superior to ACCF in terms of hospital stay, operation time, blood loss, and incidence of complications.

Keywords: anterior cervical discectomy with fusion, anterior cervical corpectomy with fusion, cervical spondylotic myelopathy, meta-analysis

\section{Introduction}

Cervical spondylotic myelopathy (CSM) is a common cause of neurologic morbidity, which can substantially decrease the quality of life. ${ }^{1,2}$ CSM can lead to symptomatic compression of spinal cord and nerve roots, ${ }^{1}$ and once CSM has been diagnosed, early 
surgical treatment should be performed to prevent further neurological deterioration. ${ }^{2}$ CSM can be treated mainly by three surgical treatments, including anterior, posterior, or combined anterior and posterior surgical approach. The choice among anterior, posterior, and combined approaches for decompression is primarily based on the sagttial alignment of the spinal column, extent of disease, location of the compressive abnormality, presence of preoperative neck pain, and previous operations. ${ }^{3}$

Anterior approaches usually comprise of anterior cervical discectomy with fusion (ACDF) and anterior cervical corpectomy with fusion (ACCF), whereas the posterior approaches include laminectomy and laminoplasty. ${ }^{4}$ Usually, the anterior approaches are chosen by the surgeons to treat patients with 1- or 2-level involvement, whereas the posterior approaches are optimal for multilevel compression when the congenital stenosis or ossification of the posterior longitudinal ligament exists. ${ }^{5,6}$ Among the anterior approaches, ACDF can decompress the anterior spinal cord, stabilize the spinal column, and is associated with a low prevalence of graft extrusion or migration. However, ACDF may not be favored for CSM because it is associated with several disadvantages, including risk of incomplete decompression, injury to the cord, limited visual exposure, and a high rate of pseudoarthrosis following an increased number of fusion surfaces. ${ }^{3,7,8}$ ACCF has been proven to have relatively good fusion rates. ${ }^{9-11}$ However, it can lead to a higher incidence of complications, including vertebral artery, ${ }^{3,8}$ dural tears, and cerebrospinal fluid leakage. ${ }^{12}$

There have been two published systematic reviews/ meta-analyses comparing ACDF versus ACCF in patients with CSM; ${ }^{13,14}$ this study expanded on the previous studies with new aspects as follows. First, our study updated the previous meta-analysis with several newly published trials. Moreover, in the literature search process, we had no imposition on the language, whereas in the meta-analysis by Han et al, they restricted the language to English. ${ }^{14}$ Thus, our results would be applied more extensively. Third, we used a meta-analysis technique to assemble the results of eligible studies, and the pooled results were presented in the format of quantitative data; whereas in the systematic review by Jiang et al, they only described the previous relevant studies and did not give a quantitative analysis for these studies. ${ }^{13}$

Although studies comparing between ACDF and ACCF have been done, the optimal approach that provides better clinical effects in the treatment of CSM remains controversial. We therefore conducted this meta-analysis based on available studies to compare the efficacy and safety between ACDF and ACCF in patients with CSM.

\section{Materials and methods Literature search}

We conducted this meta-analysis in accordance with the Preferred Reported Items For Systematic Reviews and Meta-analyses guidelines. ${ }^{15}$ PubMed, Embase, Web of Science, SinoMed (Chinese BioMedical Literature Service System, People's Republic of China), and CNKI (China National Knowledge Infrastructure, People's Republic of China) were systematically searched to identify studies that compared the efficacy and safety of ACDF and ACCF in the treatment of CSM. This search was conducted on May 12, 2015 and updated on July 27, 2015. No language limitation was imposed, but was just confined to human subjects. Search items were listed as follows: ("neck" [MeSH Terms] OR "neck" [All Fields] OR "cervical" [All Fields]) AND spondylotic [All Fields] AND ("spinal cord diseases" [MeSH Terms] OR ("spinal” [All Fields] AND "cord" [All Fields] AND “diseases" [All Fields]) OR "spinal cord diseases" [All Fields] OR "myelopathy" [All Fields] OR "bone marrow diseases" [MeSH Terms] OR ("bone" [All Fields] AND "marrow" [All Fields] AND "diseases" [All Fields]) OR "bone marrow diseases" [All Fields]) AND anterior [All Fields] AND ("neck" [MeSH Terms] OR "neck" [All Fields] OR “cervical” [All Fields]) AND corpectomy [All Fields] AND ("Nucl Eng Des/Fusion" [Journal] OR "fusion" [All Fields] OR "FUSION" [Journal] OR "fusion" [All Fields]) AND anterior [All Fields] AND ("neck" [MeSH Terms] OR "neck" [All Fields] OR "cervical" [All Fields]) AND ("diskectomy" [MeSH Terms] OR "diskectomy" [All Fields] OR “discectomy” [All Fields]) AND ("Nucl Eng Des/Fusion" [Journal] OR “fusion" [All Fields] OR "FUSION" [Journal] OR "fusion" [All Fields]). In addition, the reference lists of eligible studies and reviews were also manually searched until no potential articles were found.

\section{Study selection}

Studies were included in this meta-analysis if they met the following inclusive criteria: 1) randomized controlled trials (RCTs), cohort, or case-control studies that compared ACDF and ACCF in the treatment of CSM; 2) provided sufficient information regarding the clinical outcomes, preoperative/ postoperative parameters, or complications; and 3) the study must have a mean follow-up time of more than 6 months. The exclusion criteria were as follows: 1) mean follow-up for patients was less than 6 months and 2) did not provide 
available data for meta-analysis. Furthermore, reviews, letters, and animal studies were excluded from the final analysis. As this is a meta-analysis study, no ethics approval was required.

\section{Data extraction and quality assessment}

Two independent investigators extracted the following data from the included studies: the name of first author, publication year, country, sample size, follow-up time, patients' age and sex, the total number of patients in the ACDF and ACCF groups, duration of hospital stay, duration of operation time, blood loss, Japanese Orthopaedic Association (JOA) score before and after the operation, fusion rate, and complication rate.

We used the modified Newcastle-Ottawa Scale to conduct the quality assessment to the risk of bias in observational study. ${ }^{16}$ The scale consists of three items describing patients' selection, comparability of ACDF and ACCF groups, and assessment of the outcomes of interest. The full score was 9 , and studies with a quality score more than or equal to 6 were considered to be of high quality. The quality of an RCT was evaluated by the Jadad scale ${ }^{17}$ in the following domains: randomization ( $0-2$ points), blinding ( $0-2$ points), and dropouts and withdrawals ( $0-1$ point). The quality scale ranged from 0 to 5 points. If the score was more than 2 points, then the quality of study was considered as high. ${ }^{18}$

\section{Statistical analysis}

We compared the effects of ACDF and ACCF in CSM patients on the data from the included studies. For continuous variables (ie, duration of hospital stay, duration of operative time, blood loss, JOA score, and visual analog scale (VAS) score), the mean value and standard deviation were extracted from the included studies. Thereafter, the weighted mean difference (WMD) with 95\% confidence intervals (CIs) was calculated. For dichotomous variables (ie, incidence of complications, fusion rate), the number of events and total number of patients were extracted from the included studies. Thereafter, they were expressed as risk ratio (RR) with 95\% CIs. Finally, the WMD and RR of each study were pooled by using a fixed-effects model (Mantel-Haenszel method) ${ }^{19}$ or random-effects model (DerSimonian-Laird method). ${ }^{20}$ When significant heterogeneity was observed, the random-effects model was used to pool the data; otherwise, the fixed-effects model was used. Heterogeneity among the included studies was assessed by using the $I^{2}$ statistic and Cochrane Q chisquare test, in which $I^{2}>50 \%$ or $P<0.10$ was considered as a significant statistical heterogeneity. ${ }^{21}$ The Hirabayashi's improvement rate of JOA score was calculated according to the formula: Improvement rate $=$ (postoperative $\mathrm{JOA}$ score-preoperative JOA score)/(17-preoperative JOA score $)^{*} 100$. Begg's and Egger's tests were conducted to evaluate the presence of publication bias. ${ }^{22,23} \mathrm{~A} P$-value less than 0.05 was judged as statistically significant. All statistical analyses were performed using STATA version 12.0 (StataCorp LP, College Station, TX, USA).

\section{Results Study selection}

Based on the inclusion criteria, we initially identified a total of 487 articles from PubMed, Web of Science, Embase, SinoMed, and CNKI databases. Of these, 216 were excluded because of duplicate publications. Then, after screening the title/abstract and full texts, 230 and 23 articles were excluded, respectively, because they did not provide available or unrelated data for this meta-analysis (reviews, letters, case reports, or not relevant for our topic). Eventually, 18 studies with a total of 1,246 patients met the inclusion criteria and were included in this meta-analysis. ${ }^{7,24-40}$ The flow chart of the search strategy is shown in Figure 1.

\section{Description of these included studies}

The main characteristics of the 18 studies included in this meta-analysis are described in Table 1. All of them were

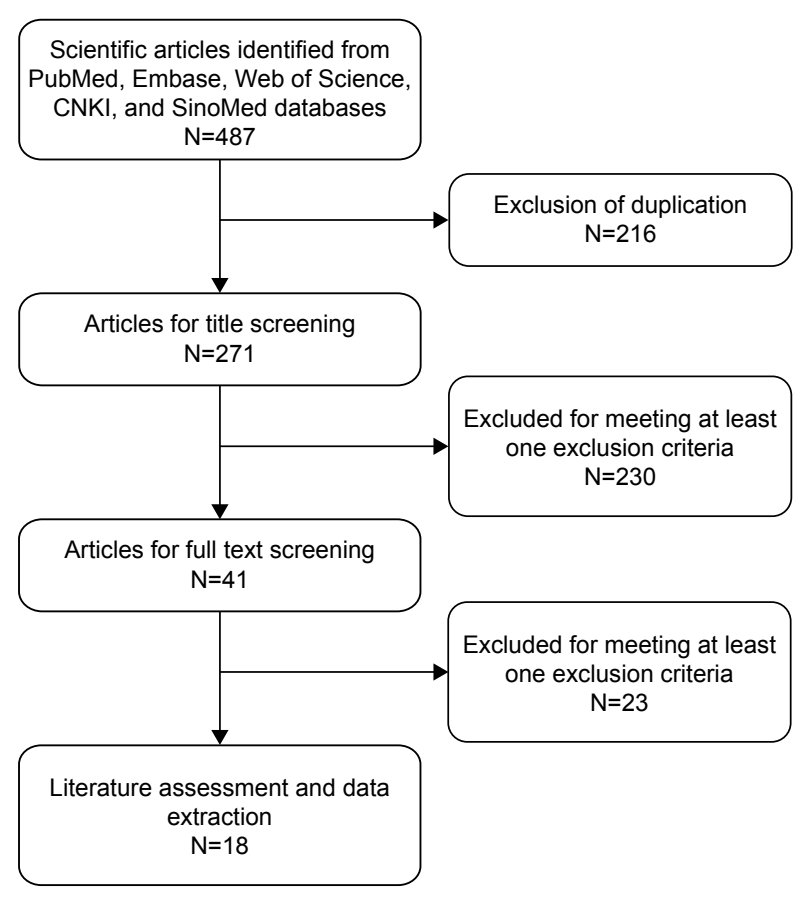

Figure I Eligibility of studies for inclusion in meta-analysis. Abbreviations: SinoMed, Chinese BioMedical Literature Service System; CNKI, China National Knowledge Infrastructure. 
Table I Baseline characteristics of patients in the trials included in the meta-analysis

\begin{tabular}{|c|c|c|c|c|c|c|}
\hline Study & Country & Surgeries & Case number & Age (years) & Follow-up (months) & NOS score \\
\hline \multirow[t]{2}{*}{ Oh et $\mathrm{al}^{7}$} & South Korea & ACDF & 14 & 52.64 & 24.9 & 8 \\
\hline & & $\mathrm{ACCF}$ & 17 & 55.12 & 27.33 & \\
\hline \multirow[t]{2}{*}{ Song et $\mathrm{a}^{24}$} & South Korea & ACDF & 25 & $50.3 \pm 7.5$ & $87.3 \pm 21.7$ & 9 \\
\hline & & $\mathrm{ACCF}$ & 15 & $54.1 \pm 9.8$ & $94.3 \pm 25.3$ & \\
\hline \multirow[t]{3}{*}{ Li et $\mathrm{al}^{25}$} & People's Republic & ACDF & 47 & NR & $79.6 \pm 20.5$ & 7 \\
\hline & of China & & & & & \\
\hline & & $\mathrm{ACCF}$ & 42 & NR & $79.6 \pm 20.5$ & \\
\hline \multirow[t]{3}{*}{ Guo et $\mathrm{al}^{26}$} & People's Republic & ACDF & 43 & $52.7 \pm 9.4$ & $37.7 \pm 7.2$ & 8 \\
\hline & of China & & & & & \\
\hline & & $\mathrm{ACCF}$ & 24 & $55.2 \pm 10.1$ & $37.3 \pm 7.3$ & \\
\hline \multirow[t]{3}{*}{ Liu et $\mathrm{a}^{27}$} & People's Republic & ACDF & 69 & $46.1 \pm 6.8$ & 26.8 & 8 \\
\hline & of China & & & & & \\
\hline & & $\mathrm{ACCF}$ & 39 & $47.8 \pm 6.4$ & 26.4 & \\
\hline \multirow[t]{2}{*}{ Uribe et $\mathrm{a}^{28}$} & USA & ACDF & 42 & 46.2 & 27.6 & 8 \\
\hline & & $\mathrm{ACCF}$ & 38 & 50 & 26.4 & \\
\hline \multirow[t]{3}{*}{ Yu et $a^{29}$} & People's Republic & ACDF & 20 & $52.75 \pm 7.81$ & 6 & 7 \\
\hline & of China & & & & & \\
\hline & & $\mathrm{ACCF}$ & 20 & $53.10 \pm 8.98$ & 6 & \\
\hline \multirow[t]{3}{*}{ Xu et $\mathrm{al}^{30}$} & People's Republic & ACDF & 22 & $32-68$ & $18 \pm 4.25$ & 8 \\
\hline & of China & & & & & \\
\hline & & $\mathrm{ACCF}$ & 15 & $38-7 \mid$ & $18 \pm 4.25$ & \\
\hline \multirow[t]{3}{*}{ Huang et $\mathrm{al}^{31}$} & People's Republic & ACDF & 18 & $45-68$ & $12-15$ & 7 \\
\hline & of China & & & & & \\
\hline & & $\mathrm{ACCF}$ & 15 & $49-70$ & $12-15$ & \\
\hline \multirow[t]{3}{*}{ Sun et $\mathrm{al}^{32}$} & People's Republic & ACDF & 24 & $35-70$ & $13-34$ & 7 \\
\hline & of China & & & & & \\
\hline & & $\mathrm{ACCF}$ & 16 & $35-70$ & $13-34$ & \\
\hline \multirow[t]{3}{*}{ Zhang et $\mathrm{al}^{33}$} & People's Republic & ACDF & 87 & $52.64 \pm 11.4$ & $24.9 \pm 24$ & 8 \\
\hline & of China & & & & & \\
\hline & & $\mathrm{ACCF}$ & 69 & $55.12 \pm 12.2$ & $27.33 \pm 20$ & \\
\hline \multirow[t]{3}{*}{ Chen $^{34}$} & People's Republic & ACDF & 23 & $58.3 \pm 7.3$ & $18.4 \pm 5.3$ & 8 \\
\hline & of China & & & & & \\
\hline & & $\mathrm{ACCF}$ & 21 & $58.6 \pm 7.4$ & $18.4 \pm 5.3$ & \\
\hline \multirow[t]{3}{*}{ Liu et a ${ }^{35}$} & People's Republic & ACDF & 27 & $56.5 \pm 9.2$ & $13.6 \pm 1.2$ & 3 (Jadad score) \\
\hline & of China & & & & & \\
\hline & & $\mathrm{ACCF}$ & 27 & $54.4 \pm 10.9$ & $|4.1 \pm| .4$ & \\
\hline \multirow[t]{3}{*}{ Hou et $\mathrm{al}^{36}$} & People's Republic & ACDF & 27 & $50.43 \pm 6.50$ & $13-34$ & 7 \\
\hline & of China & & & & & \\
\hline & & $\mathrm{ACCF}$ & 38 & $50.43 \pm 6.50$ & $13-34$ & \\
\hline \multirow[t]{3}{*}{ Huang et al ${ }^{37}$} & People's Republic & ACDF & 23 & NR & $13-36$ & 7 \\
\hline & of China & & & & & \\
\hline & & $\mathrm{ACCF}$ & 21 & NR & $13-36$ & \\
\hline \multirow[t]{3}{*}{ Zhang et $\mathrm{al}^{38}$} & People's Republic & ACDF & 15 & $50-64$ & 12 & 7 \\
\hline & of China & & & & & \\
\hline & & $\mathrm{ACCF}$ & 17 & $52-68$ & 12 & \\
\hline \multirow[t]{3}{*}{ Qi et $\mathrm{al}^{39}$} & People's Republic & ACDF & 124 & $53.8 \pm 8.5$ & $18-60$ & 8 \\
\hline & of China & & & & & \\
\hline & & $\mathrm{ACCF}$ & 94 & $54.36 \pm 7.82$ & $18-60$ & \\
\hline \multirow[t]{3}{*}{ Jia et $\mathrm{al}^{40}$} & People's Republic & ACDF & 31 & $48.83 \pm 8.12$ & $28.96 \pm 13.21$ & 8 \\
\hline & of China & & & & & \\
\hline & & $\mathrm{ACCF}$ & 36 & $49.12 \pm 7.65$ & $26.81 \pm 11.02$ & \\
\hline
\end{tabular}

Note: Age and follow-up data are expressed as either mean \pm SD or as a range.

Abbreviations: ACDF, anterior cervical discectomy with fusion; ACCF, anterior cervical corpectomy with fusion; NR, not reported; NOS, Newcastle-Ottawa Scale; $\mathrm{SD}$, standard deviation.

published in peer-reviewed journals between 2007 and 2014, of which six studies were published in international English journals ${ }^{7,24-28}$ and 12 were in Chinese core journals..$^{29-40}$ All the studies included were cohort or case-control studies except one in which the study was conducted with an RCT design. ${ }^{35}$ The sample size ranged from 31 to 218 . Among the 18 studies, 15 were conducted in People's Republic of China, ${ }^{25-27,29-40}$ two in South Korea, ${ }^{7,24}$ and one in the USA. ${ }^{28}$ 
Among the 18 studies included for meta-analysis, three studies were three-arm trials. ${ }^{26,27,38}$ In these trials, patients were divided into three groups: ACDF, ACCF, and combination of $\mathrm{ACDF}$ and ACCF. Since the data for the efficacy and safety comparison were provided separately, we then extracted the data from the ACDF and ACCF groups. The NewcastleOttawa Scale score for 17 observational studies ${ }^{7,24,34,36-40}$ ranged from 7 to 9 , and the Jadad score for one RCT ${ }^{35}$ was 3. This indicated that all the included studies were of high quality.

\section{Preoperative JOA score and postoperative JOA score}

Data of JOA score were available from 12 studies. . $24,25,27$ 29,31,32,35,36,38-40 Pooled estimates indicated that patients who underwent ACDF had a 4.05 point increase of JOA score (WMD $=4.05,95 \%$ CI: $3.40,4.71 ; P=0.000)$ at the final follow-up as compared to that at the preoperative stage. And patients who underwent ACCF had a 4.14 point increase of JOA score (WMD $=4.14,95 \%$ CI: 3.25, 5.03; $P=0.000$ ) at the final follow-up, as compared to that at the preoperative stage. However, there were no significant differences between the two groups in terms of the preoperative JOA score $(\mathrm{WMD}=0.02,95 \% \mathrm{CI}:-0.18,0.22 ; P=0.838$ ) (Figure 2$)$ and postoperative JOA score (WMD $=-0.27,95 \% \mathrm{CI}:-0.57$, $0.03 ; P=0.075$ ) (Figure 3). Hirabayashi's improvement rates for ACDF and ACCF were 58.5\% and 59.4\%, respectively.

\section{VAS score}

Two studies reported the data of VAS score. ${ }^{7,24}$ The pooled results showed that the VAS score decreased by 2.94 points in the ACDF group (WMD $=-2.94,95 \% \mathrm{CI}:-4.32,-1.56$; $P=0.000$ ) and 1.53 points in the ACCF group (WMD $=-1.53$, 95\% CI: $-4.42,1.36 ; P=0.300)$. However, there were no significant differences between the two groups in the preoperative VAS score (WMD $=1.39,95 \% \mathrm{CI}$ : -0.01 , 2.79; $P=0.052$ ) (Figure 2) and postoperative VAS score (WMD $=0.03,95 \% \mathrm{CI}:-1.44,1.50 ; P=0.970$ ) (Figure 3).

\section{Hospital stay}

Seven studies with a total number of 425 patients (34.1\% of 1,246 patients) reported the data of hospital stay. ${ }^{7,24,31,33-35,40}$ The aggregated results suggest that patients who underwent ACDF had 1.33 days less of hospital stay as compared to those who were treated with ACCF (WMD $=-1.33,95 \%$ CI: -2.29 , $-0.27 ; P=0.014$ ) (Figure 4). There was statistical heterogeneity between the individual studies ( $P=0.078, P=47.1 \%)$.

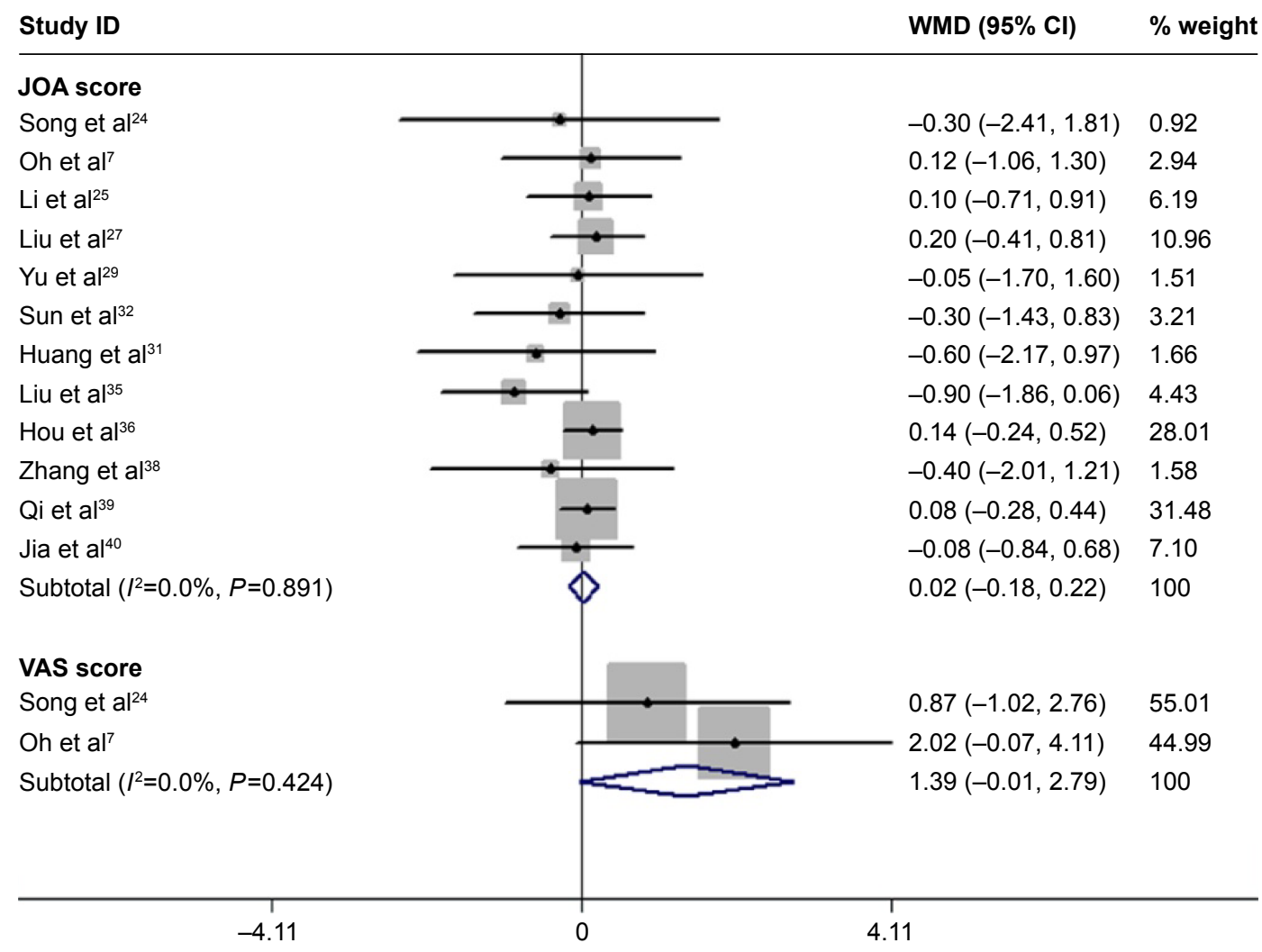

Figure 2 Comparison of anterior cervical discectomy with fusion or anterior cervical corpectomy with fusion for patients with cervical spondylotic myelopathy in terms of preoperative JOA and VAS scores.

Abbreviations: WMD, weighted mean difference; JOA, Japanese Orthopaedic Association; VAS, visual analog scale; Cl, confidence interval. 


\begin{tabular}{|c|c|c|c|}
\hline Study ID & & WMD (95\% Cl) & $\%$ weight \\
\hline \multicolumn{4}{|l|}{ JOA score } \\
\hline Song et al ${ }^{24}$ & & $0.30(-1.40,2.00)$ & 2.73 \\
\hline Oh et $\mathrm{al}^{7}$ & $\rightarrow$ & $0.53(-0.60,1.66)$ & 5.49 \\
\hline Li et $\mathrm{al}^{25}$ & & $-0.10(-0.97,0.77)$ & 8.02 \\
\hline Liu et $\mathrm{al}^{27}$ & - & $-0.40(-1.08,0.28)$ & 11.03 \\
\hline Yu et $\mathrm{al}^{29}$ & & $-1.25(-2.87,0.37)$ & 2.97 \\
\hline Sun et al ${ }^{32}$ & $\rightarrow$ & $0.20(-0.68,1.08)$ & 7.97 \\
\hline Huang et $a^{31}$ & & $-0.70(-2.54,1.14)$ & 2.37 \\
\hline Liu et $\mathrm{a}^{35}$ & - & $-0.50(-1.20,0.20)$ & 10.74 \\
\hline Hou et $a^{36}$ & & $-0.80(-1.15,-0.45)$ & 19.04 \\
\hline Zhang et al ${ }^{38}$ & & $1.50(-0.33,3.33)$ & 2.40 \\
\hline Qi et al ${ }^{39}$ & & $-0.11(-0.49,0.27)$ & 18.17 \\
\hline Jia et $\mathrm{a}^{40}$ & & $-0.31(-1.11,0.49)$ & 9.06 \\
\hline Subtotal $\left(I^{2}=38.7 \%, P=0.083\right)$ & & $-0.27(-0.57,0.03)$ & 100 \\
\hline \multicolumn{4}{|l|}{ VAS score } \\
\hline Song et $\mathrm{a}^{24}$ & & $0.80(-0.98,2.58)$ & 48.56 \\
\hline Oh et $\mathrm{al}^{7}$ & & $-0.70(-2.41,1.01)$ & 51.44 \\
\hline Subtotal $\left(I^{2}=29.8 \%, P=0.233\right)$ & -תביביבי & $0.03(-1.44,1.50)$ & 100 \\
\hline
\end{tabular}

Figure 3 Comparison of anterior cervical discectomy with fusion or anterior cervical corpectomy with fusion for patients with cervical spondylotic myelopathy in terms of postoperative JOA and VAS scores.

Note: Weights are from random-effects analysis.

Abbreviations: WMD, weighted mean difference; JOA, Japanese Orthopaedic Association; VAS, visual analog scale; Cl, confidence interval.

We performed subgroup analysis according to the region. The pooled results revealed that South Korea patients who received ACDF had 5.60 days less of hospital stay as compared to those with ACCF (WMD $=-5.60,95 \%$
CI: $-9.00,-2.19 ; P=0.001)$, whereas Chinese patients had 0.88 days less of hospital stay as compared to those with ACCF (WMD $=-0.88,95 \%$ CI: $-1.49,-0.28 ; P=0.000$ ).

There was statistical heterogeneity between the two studies

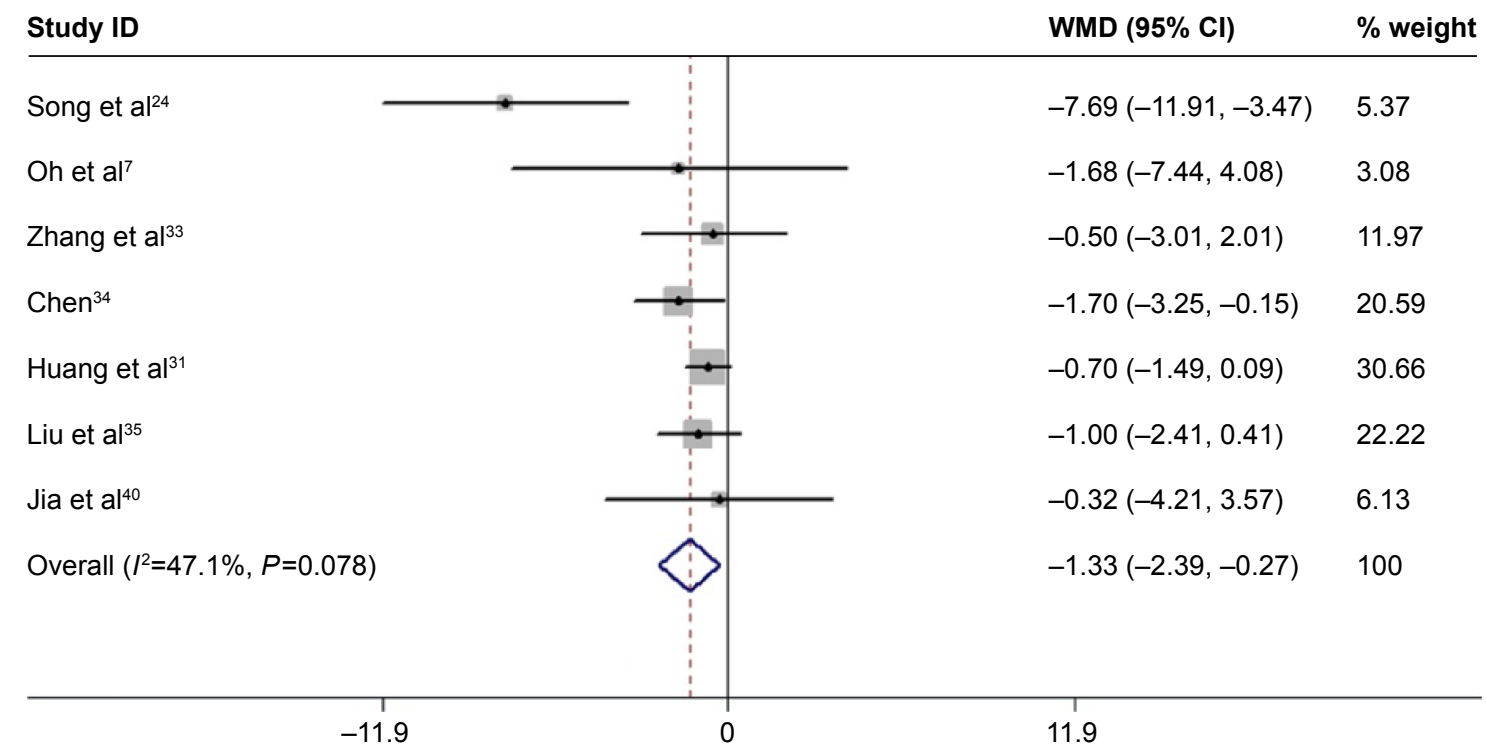

Figure 4 Comparison of anterior cervical discectomy with fusion or anterior cervical corpectomy with fusion for patients with cervical spondylotic myelopathy in terms of hospital stay.

Note: Weights are from random-effects analysis.

Abbreviations: WMD, weighted mean difference; $\mathrm{Cl}$, confidence interval. 
from South Korea $\left(P=0.099, I^{2}=63.3 \%\right)$, and no heterogeneity between the five studies from People's Republic of China $\left(P=0.831, I^{2}=0.0 \%\right)$.

The Egger's test $(P=0.205)$ and Begg's test $(P=0.108)$ revealed no publication bias.

\section{Operation time}

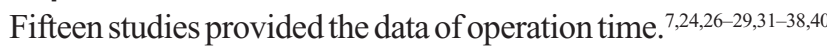
The pooled estimates revealed that patients who received ACDF had 26.9 minutes less of operating time, as compared to those who were treated with ACCF (WMD =-26.9, 95\% CI: $-46.13,-7.67 ; P=0.006$ ) (Figure 5). There was statistical heterogeneity between the individual studies $(P=0.000$, $I^{2}=95.9 \%$ ).

We performed subgroup analysis according to the region. The pooled results revealed that South Korea patients who received ACDF had 72.56 minutes less of operating time as compared to those with ACCF (WMD =-72.56, 95\% CI: $-92.83,-52.29 ; P=0.000)$, whereas Chinese patients had 26.69 minutes less of operating time (WMD =-26.69, 95\% CI: $-41.16,-12.22 ; P=0.000)$. There was no heterogeneity between the two studies from South Korea $\left(P=0.589, I^{2}=0.0 \%\right)$ and statistical heterogeneity between the 12 studies from People's Republic of China $(P=0.000$, $I^{2}=91.3 \%$ ). Since only one study reported the data of blood loss in the USA, we did not perform the subgroup analysis.

Egger's test $(P=0.89)$ and Begg's test $(P=0.33)$ revealed no publication bias.

\section{Blood loss}

Sixteen studies reported the data of blood loss..$^{7,24,26-38,40}$ Pooling these studies using a random-effects model showed that patients in the ACDF group had $119.36 \mathrm{~mL}$ less of blood loss than those in the ACCF group (WMD $=-119.36,95 \%$ CI: $-166.94,-71.77 ; P=0.000$ ) (Figure 6). There was significant heterogeneity between individual studies $(P=0.000$, $\left.I^{2}=98.2 \%\right)$.

We performed subgroup analysis according to the region. The pooled results revealed that South Korea patients who received ACDF had $425.48 \mathrm{~mL}$ less of blood loss as compared to those with ACCF (WMD $=-425.48,95 \%$ CI: $-633.17,-217.79 ; P=0.000)$, whereas Chinese patients had $95.61 \mathrm{~mL}$ less of blood loss (WMD =-95.61, 95\% CI: $-125.06,-66.17 ; P=0.000)$. There was no heterogeneity between the two studies from South Korea $(P=0.700$, $I^{2}=0.0 \%$ ), and statistical heterogeneity between the 13 studies from People's Republic of China $\left(P=0.000, I^{2}=93.3 \%\right)$.

Egger's test $(P=0.8)$ and Begg's test $(P=0.48)$ revealed no publication bias.

\begin{tabular}{|c|c|c|c|}
\hline Study ID & & WMD (95\% Cl) & $\%$ weight \\
\hline Song et $\mathrm{al}^{24}$ & & $-82.10(-122.24,-41.96)$ & 5.46 \\
\hline Oh et $\mathrm{al}^{7}$ & & $-69.29(-92.77,-45.81)$ & 6.47 \\
\hline Guo et $a^{26}$ & & $-21.80(-30.12,-13.48)$ & 7.07 \\
\hline Liu et $\mathrm{al}^{27}$ & $\rightarrow$ & $27.10(15.12,39.08)$ & 6.97 \\
\hline Uribe et $\mathrm{al}^{28}$ & $\rightarrow$ & $60.00(48.92,71.08)$ & 6.99 \\
\hline Yu et $\mathrm{al}^{29}$ & & $-18.60(-30.26,-6.94)$ & 6.98 \\
\hline Sun et $a^{32}$ & & $-55.80(-75.89,-35.71)$ & 6.64 \\
\hline Zhang et $\mathrm{al}^{33}$ & & $-31.00(-43.98,-18.02)$ & 6.94 \\
\hline Chen $^{34}$ & & $-53.40(-72.92,-33.88)$ & 6.67 \\
\hline Huang et $\mathrm{al}^{31}$ & $\longrightarrow$ & $19.20(2.37,36.03)$ & 6.79 \\
\hline Liu et $a^{35}$ & & $-51.00(-74.65,-27.35)$ & 6.46 \\
\hline Hou et al ${ }^{36}$ & & $-21.10(-35.34,-6.86)$ & 6.89 \\
\hline Huang et $\mathrm{al}^{37}$ & & $-34.00(-46.46,-21.54)$ & 6.95 \\
\hline Zhang et $\mathrm{al}^{38}$ & & $-50.00(-79.65,-20.35)$ & 6.12 \\
\hline Jia et $a^{40}$ & & $-43.86(-64.69,-23.03)$ & 6.61 \\
\hline Overall $\left(I^{2}=95.9 \%, P=0.000\right)$ & & $-26.90(-46.13,-7.67)$ & 100 \\
\hline $\begin{array}{c}1 \\
-122\end{array}$ & & $\begin{array}{c}1 \\
122\end{array}$ & \\
\hline
\end{tabular}

Figure 5 Comparison of anterior cervical discectomy with fusion or anterior cervical corpectomy with fusion for patients with cervical spondylotic myelopathy in terms of operation time.

Note: Weights are from random-effects analysis.

Abbreviations: WMD, weighted mean difference; $\mathrm{Cl}$, confidence interval. 


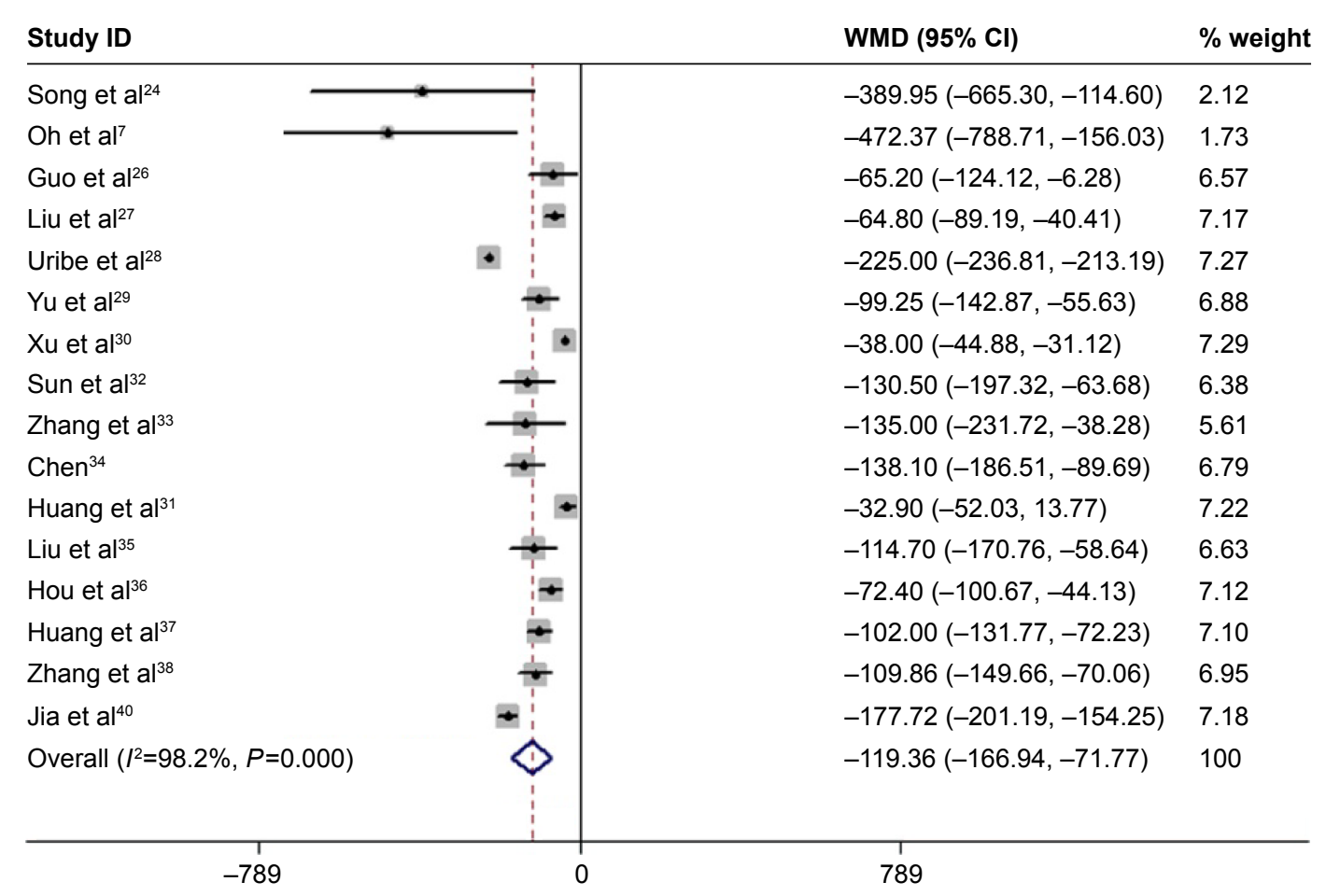

Figure 6 Comparison of anterior cervical discectomy with fusion or anterior cervical corpectomy with fusion for patients with cervical spondylotic myelopathy in terms of blood loss.

Note: Weights are from random-effects analysis.

Abbreviations: WMD, weighted mean difference; $\mathrm{Cl}$, confidence interval.

\section{Fusion rate}

Ten studies with a total number of 677 patients $(54.3 \%$ of 1,246 patients) presented the data of fusion rate. ${ }^{7,24,26-29,33,34,37,40}$ Among them, five reported a $100 \%$ of fusion rate in both ACDF and ACCF groups. ${ }^{7,29,33,34,40}$ The pooled results suggest that there was no significant difference in fusion rate between the two groups ( $\mathrm{RR}=1.04,95 \% \mathrm{CI}$ : 0.99, 1.09; $P=0.158$ ) (Figure 7).

No evidence of potential publication bias was found according to Begg's test and Egger's test (Egger's test, $P=0.917$; Begg's test, $P=0.789$ ).

\section{Complication rate}

Twelve studies with a total number of 867 patients $(69.6 \%$ of 1,246 patients) reported the data of complication. 24,26-29,32,34-37,39,40 Common complications, including donor site pain, graft dislodgment, C5 palsy, titanium mesh subsidence, dysphagia, hoarseness, hematoma, pseudoarthrosis, cerebrospinal fluid leaks, and infection, were reported in these studies. The pooled analysis indicated that there was a significant difference of complication rate between the ACDF and ACCF groups ( $\mathrm{RR}=0.51,95 \% \mathrm{CI}$ : 0.33, 0.80; $P=0.003$ ) (Figure 7). Moreover, the incidences of donor site pain ( $R R=0.21,95 \%$ CI: $0.06,0.72 ; P=0.012$ ), graft dislodgment ( $R R=0.25,95 \%$ CI: $0.09,0.73 ; P=0.012)$, C5 palsy ( $\mathrm{RR}=0.31,95 \%$ CI: 0.10 ,
0.98; $P=0.047)$, and titanium mesh subsidence $(\mathrm{RR}=0.30$, 95\% CI: $0.10,0.89 ; P=0.03$ ) were lower in the ACDF group than that in the ACCF group (Table 2).

We performed subgroup analysis according to the region. Pooled results of ten Chinese studies showed that ACDF had a lower complication rate than that of ACCF (RR $=0.44,95 \%$ CI: $0.32,0.60 ; P=0.000){ }^{26,27,29,32,34-37,39,40}$ Egger's test $(P=0.8)$ and Begg's test $(P=0.48)$ revealed no publication bias.

\section{Discussion}

The present study is a meta-analysis of studies with the objective of comparing the efficacy and safety between ACDF and ACCF in the treatment of CSM patients. Our study showed that ACDF had similar clinical outcomes with ACCF, including JOA score, VAS score, and fusion rate. However, there were significantly shorter operation time, shorter hospital stay, less blood loss, and lower complication rate in the ACDF group as compared to the ACCF group. Our study indicates that ACDF seems to be superior to ACCF in terms of safety outcomes.

Neural function outcome endpoints are important for evaluating the index for surgical treatment for CSM. In this meta-analysis, both ACDF and ACCF groups showed significant improvement on postoperative JOA and VAS scores. However, there were no significant differences between the two groups in preoperative and postoperative JOA scores, 


\begin{tabular}{|c|c|c|}
\hline Study ID & RR $(95 \% \mathrm{Cl})$ & $\%$ weight \\
\hline \multicolumn{3}{|l|}{ Fusion rate } \\
\hline Song et $\mathrm{al}^{24}$ & $0.94(0.77,1.15)$ & 6.65 \\
\hline Guo et $\mathrm{al}^{26}$ & $1.02(0.93,1.12)$ & 28.73 \\
\hline Liu et $\mathrm{al}^{27}$ & $1.06(0.98,1.15)$ & 38.41 \\
\hline Uribe et $\mathrm{al}^{28}$ & $1.06(0.95,1.18)$ & 23.96 \\
\hline Huang et $\mathrm{a}^{37}$ & $0.97(0.69,1.36)$ & 2.25 \\
\hline Oh et $\mathrm{al}^{7}$ & (Excluded) & 0.00 \\
\hline Yu et $a^{29}$ & (Excluded) & 0.00 \\
\hline Zhang et $\mathrm{a}^{33}$ & (Excluded) & 0.00 \\
\hline Chen $^{34}$ & (Excluded) & 0.00 \\
\hline Jia et $a^{40}$ & (Excluded) & 0.00 \\
\hline Subtotal $\left(I^{2}=0.0 \%, P=0.788\right)$ & $1.04(0.99,1.09)$ & 100 \\
\hline \multicolumn{3}{|l|}{ Complication rate } \\
\hline Song et a $\left.\right|^{24}$ & $1.20(0.69,2.10)$ & 16.82 \\
\hline Guo et $\mathrm{al}^{26}$ & $0.09(0.01,0.73)$ & 3.91 \\
\hline Liu et $\mathrm{al}^{27}$ & $0.50(0.28,0.88)$ & 16.58 \\
\hline Uribe et $a^{28}$ & $0.30(0.03,2.78)$ & 3.44 \\
\hline Yu et $\mathrm{al}^{29}$ & $0.06(0.01,0.41)$ & 4.39 \\
\hline Sun et $\mathrm{al}^{32}$ & $0.27(0.06,1.21)$ & 6.31 \\
\hline Chen $^{34}$ & $0.26(0.06,1.12)$ & 6.67 \\
\hline Liu et $\mathrm{al}^{35}$ & $0.80(0.25,2.61)$ & 8.79 \\
\hline Hou et $\mathrm{al}^{36}$ & $0.56(0.12,2.69)$ & 6.01 \\
\hline Huang et $\mathrm{al}^{37}$ & $0.91(0.21,4.04)$ & 6.47 \\
\hline Qi et $\mathrm{al}^{39}$ & $0.64(0.38,1.07)$ & 17.49 \\
\hline Jia et $a^{40}$ & $0.58(0.06,6.10)$ & 3.12 \\
\hline Subtotal $\left(I^{2}=46.3 \%, P=0.039\right)$ & $0.51(0.33,0.80)$ & 100 \\
\hline
\end{tabular}

Figure 7 Comparison of anterior cervical discectomy with fusion or anterior cervical corpectomy with fusion for patients with cervical spondylotic myelopathy in terms of fusion rate and complication rate.

Note: Weights are from random-effects analysis.

Abbreviations: $\mathrm{RR}$, risk ratio; $\mathrm{Cl}$, confidence interval.

indicating that patients with ACDF treatment may achieve similar neural function outcomes as those with ACCF. And there was no strong difference in the efficacy between ACDF and ACCF in the treatment of CSM.

In this meta-analysis, we found that patients treating with ACDF had obviously shorter operation time than

Table 2 Summary of the RR of complications in patients with CSM

\begin{tabular}{llll}
\hline Complications & $\mathbf{R R}$ & $\mathbf{9 5 \%} \mathbf{~ C l}$ & $\boldsymbol{P}$-value \\
\hline Donor site pain & 0.21 & $0.06,0.72$ & 0.012 \\
Graft dislodgment & 0.25 & $0.09,0.73$ & 0.012 \\
C5 palsy & 0.31 & $0.10,0.98$ & 0.047 \\
Titanium mesh subsidence & 0.30 & $0.10,0.89$ & 0.030 \\
Dysphagia & 1.07 & $0.61,1.87$ & 0.810 \\
Hoarseness & 0.91 & $0.39,2.14$ & 0.835 \\
Hematoma & 0.66 & $0.20,2.20$ & 0.502 \\
Pseudoarthrosis & 1.08 & $0.28,4.20$ & 0.911 \\
CSF leaks & 1.75 & $0.48,6.36$ & 0.398 \\
Infection & 0.47 & $0.13,1.78$ & 0.266 \\
\hline
\end{tabular}

Abbreviations: RR, risk ratio; CSM, cervical spondylotic myelopathy; CSF, cerebrospinal fluid; $\mathrm{Cl}$, confidence interval. those treating with ACCF. And this result was observed in most of the included studies. However, in two studies that conducted by Liu et $\mathrm{al}^{27}$ and Uribe et al, ${ }^{28}$ the results revealed that operation time was significantly higher in the ACDF group than that in the ACCF group. According to the previously published studies, ACCF was associated with excision of the anterior midline trough in the vertebra body down to the posterior longitudinal ligament, with removal of upper and lower adjacent discs while ACDF was involved in the elimination of the affected intervertebral disc tissue. ${ }^{7,41}$ Therefore, as compared with ACDF, ACCF was a complex procedure performed and technically more challenging and consuming time. Thus, it is not surprising to observe a longer operation time in the ACCF group than that in the ACDF group.

Our results were consistent with a previous study verifying that ACDF has a shorter hospital stay and less blood loss compared to ACCF in the treatment of CSM. ${ }^{24}$ These could be explained by the fact that ACCF was associated with a more serious spinal cord injury than $\mathrm{ACDF}$, and $\mathrm{ACDF}$ was 
also commonly regarded to be with less intraoperative blood loss; thus, patients undergoing ACDF would recover faster than those receiving ACCF. ${ }^{26,42,43}$

Among the 18 studies included in this meta-analysis, five 7,29,33,34,40 reported a complete fusion in both ACDF and ACCF groups. However, in the remaining studies, the fusion rate of $\mathrm{ACDF}$ or $\mathrm{ACCF}$ in the treatment of CSM remains controversial. Song et $\mathrm{al}^{24}$ studied 40 patients with CSM who underwent the anterior surgical treatment. They found that the fusion rate of ACDF (88\%) was lower than ACCF (93.3\%); however, the difference was not significant. ${ }^{24}$ The authors thought that the fusion may not be affected by the development of pseudoarthrosis. ${ }^{44}$ Contrary to the result, Uribe et $\mathrm{al}^{28}$ found a slightly higher fusion rate after ACDF (97.6\%) than ACCF (92.1\%). The authors attributed these findings to the higher fusion rate in the ACDF group since the fusion rate of ACCF (92.1\%) was comparable to other previous researches. ${ }^{45,46}$ Furthermore, the authors believed that the higher fusion rate of ACDF in their study was owing to the strict adherence to surgical principles of anterior cervical fusion, including preserve of the end plates, avoiding over-distraction, use of local autograft and supplemental autograft from sternal manubrium, and use of cages instead of allograft. ${ }^{28}$

Two similar systematic reviews/meta-analyses have been published comparing ACDF with ACCF. ${ }^{13,14}$ However, there were several different outcomes between theirs and ours. First, in this meta-analysis, we found that patients who received ACDF had 26.9 minutes less of operation time as compared to those receiving ACCF (WMD $=-26.9$, 95\% CI: $-46.13,-7.67 ; P=0.006)$ whereas in the study by Han et al, ${ }^{14}$ operation time between the two groups was not significant $(\mathrm{WMD}=-9.34,95 \% \mathrm{CI}:-42.99,24.31 ; P=0.59)$. Since our results were calculated based on 15 studies with 901 patients, whereas the studies by Han et al were based on six studies with 446 patients, we thought that our results would be more reliable and credible. Second, in this study, ACDF had lower incidences of several complications than $\mathrm{ACCF}$, including donor site pain ( $\mathrm{RR}=0.21,95 \% \mathrm{CI}: 0.06$, $0.72 ; P=0.012)$, graft dislodgment $(\mathrm{RR}=0.25,95 \% \mathrm{CI}: 0.09$, $0.73 ; P=0.012)$, C5 palsy $(\mathrm{RR}=0.31,95 \% \mathrm{CI}: 0.10,0.98$; $P=0.047)$, and titanium mesh subsidence $(\mathrm{RR}=0.30,95 \%$ CI: $0.10,0.89 ; P=0.03)$; whereas, in the study by Han et al, only the incidence of graft-related complication was found to be lower in the ACDF group than that in the ACCF group $(\mathrm{RR}=0.23,95 \% \mathrm{CI}: 0.09,0.64 ; P=0.005) .{ }^{14}$ Since the records of postoperative complications were variable among these studies (some reporting all complications and some reporting only the major complications), further studies are needed to identify the complication issue.

There are some potential limitations in this meta-analysis that should be taken into account. First, we admit that our study was performed based on 18 trials, and most of the trials had a relatively small sample size. As compared to larger trials, smaller trials were more likely to overestimate the treatment effect. Thus, our conclusion should be interpreted with caution. Second, we acknowledge that all these included studies except one were observational studies rather than RCT. RCT is regarded as the most efficient and highlevel evidence for clinical research, whereas observational studies have a relatively low-level clinical evidence, and would result in selection bias. Despite an RCT providing an unbiased comparison of the surgical effect, it is difficult to perform the ACDF and ACCF procedures by using a randomized controlled design because of ethical problems. Third, it should be noticed that, among the 18 studies, 15 were from People's Republic of China, which would have a potential impact on the credibility and reliability of our results. Therefore, surgeons around the world should interpret our results with caution when applying them in the clinical practice.

In conclusion, this meta-analysis suggested that there were no significant differences between ACDF and ACCF in terms of JOA score, VAS score, and fusion rate. However, as compared to ACCF, ACDF had a shorter operation time, shorter hospital stay, less blood loss, as well as lower complication rate. Therefore, ACDF may be a safer alternative to ACCF for the surgical treatment of CSM patients. However, owing to the limitations in this study, more studies with high quality, larger sample size, and long-term follow-up are still needed to confirm our results.

\section{Acknowledgment}

The study was funded by the Capital Health Development Special Scientific Research Projects (2014 2 2023), Beijing, People's Republic of China.

\section{Disclosure}

The authors report no conflicts of interest in this work.

\section{References}

1. Toledano M, Bartleson JD. Cervical spondylotic myelopathy. Neurol Clin. 2013;31(1):287-305.

2. Lebl DR, Hughes A, Cammisa FP Jr, O'Leary PF. Cervical spondylotic myelopathy: pathophysiology, clinical presentation, and treatment. HSS J. 2011;7(2):170-178.

3. Rao RD, Gourab K, David KS. Operative treatment of cervical spondylotic myelopathy. J Bone Joint Surg Am. 2006;88(7):1619-1640. 
4. Cunningham MR, Hershman S, Bendo J. Systematic review of cohort studies comparing surgical treatments for cervical spondylotic myelopathy. Spine (Phila Pa 1976). 2010;35(5):537-543.

5. Yalamanchili PK, Vives MJ, Chaudhary SB. Cervical spondylotic myelopathy: factors in choosing the surgical approach. Adv Orthop. 2012; 2012:783762.

6. Matz PG, Anderson PA, Groff MW, et al. Cervical laminoplasty for the treatment of cervical degenerative myelopathy. J Neurosurg Spine. 2009;11(2):157-169.

7. Oh MC, Zhang HY, Park JY, Kim KS. Two-level anterior cervical discectomy versus one-level corpectomy in cervical spondylotic myelopathy. Spine (Phila Pa 1976). 2009;34(7):692-696.

8. Iwasaki M, Kawaguchi Y, Kimura T, Yonenobu K. Long-term results of expansive laminoplasty for ossification of the posterior longitudinal ligament of the cervical spine: more than 10 years follow up. J Neurosurg. 2002;96(2 Suppl):180-189.

9. Gore DR. The arthrodesis rate in multilevel anterior cervical fusions using autogenous fibula. Spine (Phila Pa 1976). 2001;26(11):1259-1263.

10. Hilibrand AS, Fye MA, Emery SE, Palumbo MA, Bohlman HH. Increased rate of arthrodesis with strut grafting after multilevel anterior cervical decompression. Spine (Phila Pa 1976). 2002;27(2): $146-151$.

11. Hwang SL, Lee KS, Su YF, et al. Anterior corpectomy with iliac bone fusion or discectomy with interbody titanium cage fusion for multilevel cervical degenerated disc disease. J Spinal Disord Tech. 2007; 20(8):565-570.

12. Cloward RB. The anterior approach for removal of ruptured cervical disks. 1958. J Neurosurg Spine. 2007;6(5):496-511.

13. Jiang S, Jiang L, Dai L. Anterior cervical discectomy and fusion versus anterior cervical corpectomy and fusion for multilevel cervical spondylosis: a systematic review. Arch Orthop Trauma Surg. 2012; 132:155-161.

14. Han Y, Liu Z, Wang S, et al. Is anterior cervical discectomy and fusion superior to corpectomy and fusion for treatment of multilevel cervical spondylotic myelopathy? A systemic review and meta-analysis. PLoS One. 2014;9(1):e87191.

15. Moher D, Liberati A, Tetzlaff J, Altman DG. Preferred reporting items for systematic reviews and meta-analyses: the PRISMA statement. PLoS Med. 2009;6(7):e1000097.

16. Wells G, Shea B, O.c. D. The Newcastle-Ottawa Scale (NOS) for assessing the quality of nonrandomized studies in meta-analyses. 3rd Symposium on Systematic Reviews: Beyond the Basics; Centre for Statistics in Medicine, Oxford; 2000.

17. Jadad AR, Moore RA, Carroll D, et al. Assessing the quality of reports of randomized clinical trials: is blinding necessary? Control Clin Trials. 1996;17(1):1-12.

18. Kjaergard LL, Villumsen J, Gluud C. Reported methodologic quality and discrepancies between large and small randomized trials in metaanalyses. Ann Intern Med. 2001;135(11):982-989.

19. Mantel N, Haenszel W. Statistical aspects of the analysis of data from retrospective studies of disease. J Natl Cancer Inst. 1959;22(4): 719-748.

20. DerSimonian R, Laird N. Meta-analysis in clinical trials. Control Clin Trials. 1986;7(3):177-188.

21. Higgins JP, Thompson SG, Deeks JJ, Altman DG. Measuring inconsistency in meta-analyses. BMJ. 2003;327(7414):557-560.

22. Begg CB, Mazumdar M. Operating characteristics of a rank correlation test for publication bias. Biometrics. 1994;50(4):1088-1101.

23. Egger M, Davey Smith G, Schneider M, Minder C. Bias in meta-analysis detected by a simple, graphical test. BMJ. 1997;315(7109):629-634.

24. Song KJ, Lee KB, Song JH. Efficacy of multilevel anterior cervical discectomy and fusion versus corpectomy and fusion for multilevel cervical spondylotic myelopathy: a minimum 5-year follow-up study. Eur Spine J. 2012;21(8):1551-1557.

25. Li J, Zheng Q, Guo X, et al. Anterior surgical options for the treatment of cervical spondylotic myelopathy in a long-term follow-up study. Arch Orthop Trauma Surg. 2013;133(6):745-751.
26. Guo Q, Bi X, Ni B, et al. Outcomes of three anterior decompression and fusion techniques in the treatment of three-level cervical spondylosis. Eur Spine J. 2011;20(9):1539-1544.

27. Liu Y, Hou Y, Yang L, et al. Comparison of 3 reconstructive techniques in the surgical management of multilevel cervical spondylotic myelopathy. Spine (Phila Pa 1976). 2012;37(23):E1450-E1458.

28. Uribe JS, Sangala JR, Duckworth EA, Vale FL. Comparison between anterior cervical discectomy fusion and cervical corpectomy fusion using titanium cages for reconstruction: analysis of outcome and longterm follow-up. Eur Spine J. 2009;18(5):654-662.

29. Yu Y, Gong W, Xin B, Yuan F, Li Q. The comparison of therapeutic efficacy between two operative methods for the treatment of two-adjacentlevel CSM. J Qiqihar Med College. 2007;28(23):2821-2823.

30. Xu J, Tian J, Xu C, Zheng W, Li W, Tao T. Comparison of two different surgical methods for multi-level of cervical spondylotic myelopathy. J Clin Orthop. 2008;11(4):312-315.

31. Huang X, Fang S, Wang X, Sun J, Xu L. A comparison study of two methods for treating two-level cervical spondylitic myelopathy. Anhui Med J. 2014;35(4):450-453.

32. Sun Z, He B, Jiang J. Comparison between anterior cervical discectomy fusion and cervical corpectomy fusion in the treatment of cervical spondylotic myelopathy. Chin J Bone Joint Injury. 2013;28(3):240-241.

33. Zhang W, Chen D. Yang L, et al. Clinical results of anterior cervical discectomy or corpectomy in 2-level cervical spondylotic myelopathy. Orthop J China. 2011;19(3):181-183.

34. Chen C. Curative effect analysis of two kinds of anterior decompression and fusion methods for double cervical spindylotic myelopathy. $J$ Reg Anat Oper Surg. 2014;23(3):262-265.

35. Liu Y, Chen L, Gu Y, Xu Y, Yang H, Tang T. Comparison of two anterior decompression bone fusion treatments plus titanium plate implantation for two-level cervical spondylotic myelopathy. J Clin Rehabil Tissue Eng Res. 2011;15(4):597-601.

36. Hou S, Shen Y, Wang L, Zhang J, Sun X. A follow-up study of two anterior surgical interventions for multi-segmental cervical spondylotic myelopathy. Orthop J China. 2014;22(7):594-600.

37. Huang S, Liu Z, Luo Z, et al. The comparison of two anterior procedure for treating cervical spondylotic myelopathy. Pract Clin Med. 2007; $8(8): 49-51$.

38. Zhang S, Zhang Z, Liu Y, et al. Case-control study of two methods in treating two-level cervical spondylitic myelopathy. Chin J Bone Joint Injury. 2013;28(7):604-606.

39. Qi M, Wang X, Liu Y, et al. Comparative analysis of complications of different anterior decompression procedures for treating multilevel cervical spondylotic myelopathy. Chinese J Spine Spinal Cord. 2012; 22:963-968.

40. Jia X, Tan Z, Yang B, Yang M, Wan G. Comparison between singlelevel cervical corpectomy and two-level discectomy in two-adjacentlevel cervical spondylotic myelopathy. Orthop J China. 2012;20(21): 1931-1934.

41. Baron EM, Young WF. Cervical spondylotic myelopathy: a brief review of its pathophysiology, clinical course, and diagnosis. Neurosurgery. 2007;60(1 Supp1):S35-S41.

42. Park HK, Jho HD. The management of vertebral artery injury in anterior cervical spine operation: a systematic review of published cases. Eur Spine J. 2012;21(12):2475-2485.

43. Zhang JD, Xia Q, Ji N, Liu YC, Han Y, Ning SL. Transient paralysis shortly after anterior cervical corpectomy and fusion. Orthop Surg. 2013;5(1):23-28.

44. DePalma AF, Rothman RH, Lewinnek GE, Canale ST. Anterior interbody fusion for severe cervical disc degeneration. Surg Gynecol Obstet. 1972;134(5):755-758.

45. Thalgott JS, Xiongsheng C, Giuffre JM. Single stage anterior cervical reconstruction with titanium mesh cages, local bone graft, and anterior plating. Spine J. 2003;3(4):294-300.

46. Majd ME, Vadhva M, Holt RT. Anterior cervical reconstruction using titanium cages with anterior plating. Spine (Phila Pa 1976). 1999;24(15):1604-1610. 


\section{Publish your work in this journal}

Therapeutics and Clinical Risk Management is an international, peerreviewed journal of clinical therapeutics and risk management, focusing on concise rapid reporting of clinical studies in all therapeutic areas, outcomes, safety, and programs for the effective, safe, and sustained use of medicines. This journal is indexed on PubMed Central, CAS,

EMBase, Scopus and the Elsevier Bibliographic databases. The manuscript management system is completely online and includes a very quick and fair peer-review system, which is all easy to use. Visit http://www.dovepress.com/testimonials.php to read real quotes from published authors.

Submit your manuscript here: http://www.dovepress.com/therapeutics-and-clinical-risk-management-journal 